\title{
Correlation between Bhalla score and spirometry in children and adolescents with Cystic Fibrosis
}

\author{
Flavia Fajardo Linhares Pereira ${ }^{1 *}$, Cassio da Cunha Ibiapina² ${ }^{2}$ Cristina Gonçalves Alvim³ ${ }^{3}$ Paulo Augusto Moreira Camargos ${ }^{4}$, \\ Reginaldo Figueiredo ${ }^{5}$, Jesiana Ferreira Pedrosa ${ }^{6}$ \\ ${ }^{1}$ Masters in child and adolescent Health at the Federal University of Minas Gerais (UFMG). Specialization in radiology and diagnostic imaging at the Santa Casa de Belo Horizonte/Faculty of Medical Sciences of Minas \\ Gerais. Residency in pediatrics at the Hospital General Israel Pinheiro (IPSEMG). Degree in medicine at the Federal University of Juiz de Fora \\ ${ }^{2}$ Doctor of Health Sciences, UFMG, Professor of the Faculty of Medicine, UFMG \\ ${ }^{3} \mathrm{PhD}$ by UFMG and Professor College of Medicine, UFMG \\ ${ }^{4}$ Post-doctorate at the Université Pierre et Marie Curie and professor at the Faculty of Medicine at UFMG. \\ ${ }^{5}$ Doctor of medicine at the Paulista School of Medicine (UNIFESP) and professor at the Faculty of Medicine at UFMG. \\ ${ }^{5}$ Master at UFMG and professor at the Faculty of Medicine, UFMG.
}

Work conducted at the Federal University of Minas Gerais, Belo Horizonte, MG,

Article received: $10 / 23 / 2012$ Accepted for publication: $1 / 9 / 2014$

*Correspondence: Hospital das Clínicas da Universidade Federal de Minas Gerais Address: Av. Prof. Alfredo Balena, 190 Sala 4061 - Santa Efigênia Belo Horizonte, MG, Brazi ZIP Code: 30130-100 Phone: +55 31 3409-9773 Mobile: +55 31 9128-5463 Fax: +55 3132489664 flavia.fajardo@ig.com.br

http://dxdoi.0rg/10.1590/1806-9282.60.03.009 Conflict of interest: none

\section{SUMMARY}

Objective: to correlate the findings of high resolution computed tomography of the chest based on the Bhalla score with the clinical data and spirometry in children and adolescents with cystic fibrosis, and to study the concordance between two radiologists for the Bhalla score and its categories.

Methods: we evaluated the medical records of 23 patients from the outpatient clinic. The items evaluated included age, weight, height, height/age Z-score, weight/ age $\mathrm{Z}$-score, body mass index (BMI), $\mathrm{O}_{2}$ saturation, spirometry and Bhalla score. Results: the patients had a mean age of 17.4 years \pm 5.7 years, with fifteen females and eight males. There was good correlation between Bhalla score and spirometry (FVC-r $=0.718$, $\mathrm{p}<0.001$; FEV1-r=0.830, $\mathrm{p}<0.001$; FEF25-75\%-r $=0.786$, $\mathrm{p}<0.001 ; \mathrm{FEV} 1 / \mathrm{FVC}-\mathrm{r}=0.714, \mathrm{p}<0.001)$. It was also noted that some patients with FEF25-75\%> 70\% already had changes in their final Bhalla score. In the analysis of the concordance between the examiners a Kappa coefficient of 0.81 ( $\mathrm{p}$ $<0.001$ ) was found, and an intraclass correlation coefficient of 0.98 .

Conclusion: a good correlation between Bhalla scores with spirometry confirmed its usefulness in evaluating and monitoring patients with cystic fibrosis, given it can be used both in patients who are unable to perform spirometry as well as for a pooled analysis of the two examinations since the HRCT scans show early changes in patients with normal function tests.

Uniterms: cystic fibrosis, tomography, spirometry, child, adolescent.

\section{INTRODUCTION}

Individuals with cystic fibrosis (CF) undergo constant multiprofessional monitoring and require standardization of treatment in order for the most subtle improvements or deteriorations in their clinical condition can be noted, with the minimum possible variation between examiners.

In this context, various authors have been interested in developing scores to evaluate the development of the disease, known as scores of the severity of cystic fibrosis and scores for evaluating radiological and tomographic changes. ${ }^{1-6}$ The use of scores enables the longitudinal evaluation of patients and standardized comparisons between them, and is therefore useful both at the clinical and research areas. ${ }^{1-3}$
Since publication of the classic work by Shwachman and Kulczycki in 1958, various other scores have been developed and published. ${ }^{1-6}$

As pulmonary insufficiency is related to the majority of deaths for patients with CF, a specific evaluation of pulmonary impairment would be recommendable and, given these circumstances, some authors have been interested in developing scores based on radiological findings using chest radiography or tomography. ${ }^{7}$

It is important to reiterate that high resolution computed tomography (HRCT) of the thorax is the ideal method owing to the characteristics of pulmonary impairment 
in cystic fibrosis, given that it is recommended for evaluation of the lung parenchyma.

The major concern at present in relation to the use of HRCT relates to the issue of ionizing radiation and especially the amount of radiation to which the patient is exposed throughout their life, resulting from multiple examinations, particularly when considering a chronic pulmonary disease such as Cystic Fibrosis. Within this perspective, studies have been conducted in an attempt to reduce doses while maintaining the quality of the images. ${ }^{8,9}$

A classic work by Lucaya et al. evaluated the effect of the reduction of this dose on the quality of the images and standards the so-called "low dose HRCT". Low dose HRCT presents a significant reduction in the dose of radiation received by the patient $(72 \%$ when using $50 \mathrm{mAs}$ and $80 \%$ when using $34 \mathrm{mAs}$ ) compared to the exam with the usual dose $(180 \mathrm{mAs}) .{ }^{23}$ It is important to note that the said study was conducted with children and young adults submitted to low dose HRCT, and not necessarily suffering from cystic fibrosis.

Monitoring pulmonary changes, however, is not only based on imaging examinations. Tests of pulmonary function have also been used with this objective over the years. ${ }^{2}$

In the literature it is possible to find works comparing the different clinical/radiological and tomographic scores and pulmonary function tests. In the majority of cases, a positive correlation can be noted between them, with the exception of patients with diseases considered as mild, who may present alterations in the tomography examinations and normal pulmonary function tests. ${ }^{8-10}$ Comparing the different evaluation parameters of pneumonopathy in $\mathrm{CF}$ is important for understanding the evolution of the changes and establishing criteria for realizing preliminary and therapeutic interventions at the appropriate time.

In recent years, owing to advancements in nutritional support, appropriate treatment of chronic colonization and exacerbations as well as recent neonatal triage, the survival curve of cystic fibrosis patients has improved. On the other hand, there is no standardized protocol about the age for conducting the first tomography or the frequency at which this should be conducted. This issue is crucial considering the amount of ionizing radiation to which the patient is exposed throughout life, as many of them undergo regular radiological examinations. Therefore, studies that evaluate the correlation between pulmonary function and chest tomography present high clinical applicability.

The objective of this study was to correlate structural pulmonary changes from chest tomography using the Bhalla score with the pulmonary function evaluated using spirometry in children and adolescents with cystic fibrosis.

\section{Methods}

The study was planned with a review of all of the medical record for patients being monitored at the Cystic Fibrosis Outpatient Clinic at the Federal University of Minas Gerais (AFC/UFMG). In the AFC/UFMG service proto$\mathrm{col}$, the realization of the first tomography is recommended at six years, an age at which the majority of children are also able to undertaken spirometry.

The inclusion criteria were defined as the realization of at least one chest tomography examination and one spirometry examination in the same month. The exclusion criteria were the interval between the tomography and spirometry with an interval of over 1 month, spiral $\mathrm{CT}$, without high resolution or non-recovery of examinations, given that the study was retrospective.

\section{High Resolution Computed Tomography}

The HRCT examinations were conducted at the Federal University of Minas Gerais Hospital das Clínicas using Somaton AR-T (Siemens) and Auklet (Toshiba) devices. The images were obtained during inhalation for all patients and upon exhalation for some, using 1.5 to $2.0 \mathrm{~mm}$ collimation, $10 \mathrm{~mm}$ intervals and $120 \mathrm{kV}$ and $160 \mathrm{mAs}$. The images were reconstructed using a high resolution algorithm and documented with appropriate windows for evaluation of pulmonary parenchyma.

As not all patients had been submitted to cross sections during exhalation, only images acquired during inhalation were considered.

\section{HRCT evaluation score}

The HRCTs were evaluated independently by two radiologists, using the Bhalla score. ${ }^{6}$ The items evaluated were: a) severity of bronchiectasis; b) peribronchial thickening; c) extent of bronchiectasis (number of lung segments); d) extent of mucus plugs (number of lung segments); e) abscesses or sacculations (number of lung segments); $f$ ) generalities of the bronchial division involved (bronchiectasis/plug); g) number of bubbles; h) emphysema (number of lung segments); i) collapse/consolidation.

The points in each category vary from zero to three and the final result can be subtracted from 25 to adapt the score to inclusion in the Shwachman-Kulczycki score. The initial $\mathrm{P}$ is added to the final result when mucous plugs are present, and $\mathrm{T}$ when there is peribronchial thickening. The Bhalla score is presented in Table 1. Results are classified as excellent when between 21 and 25 points, good when between 20 and 16 points, mild between 11 and 15 points, moderate between 6 and 10 points, and serious between 0 and 5 points. 


\section{TABLE 1 Bhalla Score}

\begin{tabular}{|c|c|c|c|c|}
\hline Category & 0 & 1 & 2 & 3 \\
\hline Severity of bronchiectasis & absent & $\begin{array}{l}\text { Mild (light subtly greater } \\
\text { than the adjacent vessel) }\end{array}$ & $\begin{array}{l}\text { Moderate (light } 2 \text { to } 3 \text { times } \\
\text { higher than the adjacent } \\
\text { vessel) }\end{array}$ & $\begin{array}{l}\text { Severe (light } 3 \text { times higher } \\
\text { than the adjacent vessel) }\end{array}$ \\
\hline Peribronchial thickening & absent & $\begin{array}{l}\text { Mild (thickening of the } \\
\text { wall equal to the vessel) }\end{array}$ & $\begin{array}{l}\text { Moderate (greater thickening/ } \\
\text { doubling of the vessel) }\end{array}$ & $\begin{array}{l}\text { Severe (thickening } 2 \text { times } \\
\text { greater than the vessel) }\end{array}$ \\
\hline $\begin{array}{l}\text { Extent of the bronchiectasis } \\
\text { (number of lung } \\
\text { segments) }\end{array}$ & absent & $1-5$ & $6-9$ & $>9$ \\
\hline $\begin{array}{l}\text { Extent of mucus plugs } \\
\text { (number of lung segments) }\end{array}$ & absent & $1-5$ & $6-9$ & $>9$ \\
\hline $\begin{array}{l}\text { Abscesses or sacculations } \\
\text { (number of lung segments) }\end{array}$ & absent & $1-5$ & $6-9$ & $>9$ \\
\hline $\begin{array}{l}\text { Generalities of the bronchial } \\
\text { division involved (bronchiectasis } \\
\text { /plug) }\end{array}$ & absent & Over the $4^{\text {th }}$ generation & Over the $5^{\text {th }}$ generation & $\begin{array}{l}\text { Over the } 6^{\text {th }} \text { generation and } \\
\text { distal }\end{array}$ \\
\hline Number of bubbles & absent & $\begin{array}{l}\text { Unilateral } \\
\text { (none > 4) }\end{array}$ & $\begin{array}{l}\text { Bilateral } \\
\text { (none > 4) }\end{array}$ & $>4$ \\
\hline $\begin{array}{l}\text { Emphysema } \\
\text { (number of lung segments) }\end{array}$ & absent & $1-5$ & $>5$ & \\
\hline $\begin{array}{l}\text { Collapse/ } \\
\text { consolidation }\end{array}$ & absent & Subsegmental & $\begin{array}{l}\text { Segmental/ } \\
\text { lobar }\end{array}$ & \\
\hline
\end{tabular}

\section{Clinical evaluation}

Weight, height, BMI, height/age and weight/age Z-scores and $\mathrm{O}_{2}$ were used for clinical evaluation.

\section{Pulmonary function tests}

The pulmonary function tests were conducted at the Pulmonary Function Laboratory at the Federal University of Minas Gerais Hospital das Clínicas and the following data was used in the analysis: a) forced vital capacity (FVC); b) forced expiratory volume in one second (FEV1); c) forced expiratory flow between 25 and $75 \%$ (FEF 25-75\%); d) FEV1/FVC ratio x 100. The recommendations of the American Thoracic Society and Polgar, Knudson and Pereira equations were used as reference values. $^{11-14}$

\section{Statistical analysis}

The concordance between the two radiologists for the final Bhalla score, as well as for each category it composes was analyzed by calculating the kappa coefficient.
The correlation between the Bhalla score and its components, the pulmonary function tests and other characteristics of interest were tested using the Spearman correlation coefficient, given that the assumption of normality was violated.

The average evaluation by the two radiologists was used for the Bhalla score.

\section{Results}

The records of 144 patients were analyzed. After analyzing the data collected, 53 patients had realized tomography and spirometry. Patients that had conducted spiral chest tomography, without high resolution $(\mathrm{N}=3)$, patients whose films were not available for analysis and patients whose interval between tomography and spirometry was greater than 30 days $(\mathrm{N}=27)$ were excluded from the 53 eligible patients $(\mathrm{N}=27)$. The final sample was therefore constituted by 23 patients.

The clinical characteristics of the population studied are presented in Table 2 . 
TABLE 2 Characteristics of the population studied

\begin{tabular}{l|l|l|l} 
Characteristics & $\mathrm{n}$ & \multicolumn{1}{|c}{ Mean } & \multicolumn{1}{c}{ SD } \\
\hline Age (years) & 23 & 17.45 & 5.75 \\
\hline Weight (kg) & 23 & 43.42 & 13.66 \\
\hline Height (cm) & 23 & 152.1 & 14.8 \\
\hline Height/age Z-score & 23 & -1.3 & 1.5 \\
\hline Weight/age Z-score & 23 & -1.6 & 2.6 \\
\hline BMI & 23 & 18.5 & 3.1 \\
\hline O2 Saturation & 23 & 95.3 & 2.1 \\
\hline Shwachman - Kulczycki Score & 23 & 80 & 16.1 \\
\hline Bhalla Score (R1) & 23 & 16.8 & 7 \\
\hline Bhalla Score (R2) & 23 & 17 & 6.6 \\
\hline Bhalla Score (R1 R2 average) & 23 & 16.9 & 6.7 \\
\hline FVC\% & 23 & 87.1 & 20.5 \\
\hline FEV1\% & 23 & 74.2 & 23.7 \\
\hline FEF 25-75\% & 23 & 54.9 & 32.8 \\
\hline FEV1/FVC x 100 & 23 & 74.2 & 12.6 \\
\hline SD S & & &
\end{tabular}

SD: standard deviation.

The median age of the population studied was 16.5 years.

\section{Cultures}

Nine of the patients studied (39.1\%) were colonized by Pseudomonas aeruginosa, being three (13\%) by the mucoid strain, fifteen (65.2\%) by Staphylococcus aureus, and three $(13 \%)$ were not colonized.

\section{Concordance between radiologists}

A very good concordance between radiologists was found for the Bhalla score, with a kappa coefficient of 0.81 and an intraclass correlation coefficient (ICC) of 0.98 , which classified it as adequate (ICC equal to or greater than 0.80).

Relationship between Bhalla scores and pulmonary function tests

A statistically significant positive correlation was identified between the Bhalla score and pulmonary function tests.

TABLE 3 Correlation between the Bhalla score and pulmonary function tests

\begin{tabular}{l|l|l}
\multirow{2}{*}{ Characteristics } & \multicolumn{2}{|l}{ Bhalla Score } \\
\cline { 2 - 3 } & $r$ & P-value \\
\hline FVC\% & 0.718 & $<0.001$ \\
\hline FEV\% & 0.830 & $<0.001$ \\
\hline FEF 25-75\% & 0.786 & $<0.001$ \\
\hline FEV1/FVC $\times 100$ & 0.714 & $<0.001$ \\
\hline
\end{tabular}

\section{Discussion}

The results found in this study prove the hypothesis that the Bhalla score represents a good correlation with pulmonary function tests and can be an ally in the evaluation of pulmonary structural changes.

In a study using the same score, Demirkazik et al. evaluated 14 patients from a group of 40 that had HRCTs compared to the clinical and radiographic categories of the Shwachman-Kulczycki score and pulmonary function tests. The age range varied from five months to 18 years, with all patients undergoing pulmonary function tests aged over six years. A good correlation was found between the Bhalla score and FVC $(r=0.71$ and $p=0.004)$ and the FEV1 $(r=0.66$ and $p=0.01)$. These findings correspond to the present study, which presented a strong and positive correlation for $\mathrm{FVC}(\mathrm{r}=0.718, \mathrm{p}<0.001)$ and FEV1 $(\mathrm{r}=0.830, \mathrm{p}<0.001) .{ }^{10}$

On the other hand, Helbich et al. evaluated the tomography of 107 patients with an average age of $14.5 \pm$ 7.3 years at four different times. There was a weak correlation ( $\mathrm{r}=0.25$ and $\mathrm{p}<0.0001)$ between the tomography and the pulmonary function tests, and while the HRCT showed significant structural changes, the spirometry manifested minimal progression or slight improvement on the standard. ${ }^{15}$

More recently, with the objective of investigating the relationship between non-invasive inflammatory markers, function tests and pulmonary structural changes, Robroeks et al. studied 34 patients with average age of 12.6 years \pm 4.4 using the score described by Brody et al. ${ }^{9}$ and found a strong correlation between the final score and the FVC $(r=-0.73, p<0.001)$, FEV1 $(r=-077, p<0.001)$ and FEV1/ FVC $(r=-0.43, p<0.001) .{ }^{11}$ Likewise, in 22 patients with an average age of 22 years \pm 5.9 and using a modified Bhalla score, Dodd et al. found a significant correlation between the final score and the FEV1 $(\mathrm{r}=-0.40, \mathrm{p}<0,05) .{ }^{18}$ Furthermore, Marchant et al., in an evaluation of 16 patients aged under 12 years with the objective of comparing the Bhalla and Nathanson scores found a significant correlation between the final Bhalla score and the FEV1 $(r=-0.65$, $\mathrm{p}=0.012)$ and $\mathrm{FVC}(\mathrm{r}=-0.57, \mathrm{p}=0.032) .{ }^{19}$

However, analyzing the scores and function tests of each patient in isolation and taking into consideration that the FEF $25-75 \%$ is the parameter that causes most early changes in $\mathrm{CF}$, it was verified that 11 of the 23 patients studied presented an FEF $25-75 \%$ above $70 \%$. Despite the final Bhalla score being over 16 in these cases or being classified as good or excellent, the letter $\mathrm{T}$ was added to the final score of 7 patients, indicating the presence of peribronchial thickening, and bronchiectasis was recorded in 4 
patients by the two radiologists. ${ }^{16,17}$ The findings in this study are reflected in the literature and a study by Marchant et al., given that all of the 16 patients head bronchiectasis, including 5 who presented normal pulmonary function tests, showing that the examinations should be complementary and should not substitute one another. ${ }^{19}$

Within the same perspective, De Jong et al. evaluated the HRCTs and pulmonary function tests of 48 patients that were conducted when they had an average age of 11.05 years \pm 3.30 and repeated after a two year interval. The HRCTs were evaluated using five different scores (Castile, Brody, Helbich, Santamaria and Bhalla). ${ }^{19}$ The authors verified that while there was deterioration in the HRCT findings in all scores used, the function tests remained unchanged or showed improvements. Furthermore, some patients with normal pulmonary function tests presented structural changes in the HRCT.

This last finding reinforces the importance of HRCT in monitoring patients with $\mathrm{CF}$, suggesting its use in order to detect early structural changes regardless of the results of pulmonary function tests.

The concordance between examiners for the total Bhalla score in the present study was considered very good by the kappa coefficient $(0.81, \mathrm{p}<0.001)$ and the ICC was considered adequate $(0.98)$. These are similar results to those of Cademartiri et al., in which the Bhalla score was used to independently evaluate 145 tomographies by three radiologists. ${ }^{21}$ The average age of patients was 15.6 years $\pm 8,4$. The ICC was 0.99 between observers 1 and 2,1 and 3,2 and 3 and between all three observers, with $p=0.001$ for all analyses.

\section{Conclusion}

The evaluation of pulmonary disease in patients with CF should include different clinical and preliminary methods, enabling an improvement in the effectiveness of treatment aiming at containing the progression of the disease.

In recent years, greater ease of access to computed tomography has enabled this test to be incorporated into the routine assessment of patients, presenting essential information about the structural changes that occur in the airways and pulmonary parenchyma, with greater accuracy than assessment by plain radiography. However, the high dose of ionizing radiation, mainly due to the repetition of examinations, raises questions regarding the best time to start implementation, as well as its frequency.

We should reiterate the finding of peribronchial thickening and mucous plugs in patients with preserved lung function (FEF 25-75 > 70\%), confirming the need for a joint analysis between high-resolution $\mathrm{CT}$ and spirometry for better monitoring and early intervention.

In regards to frequency, it is reasonable to infer that patients with stable and unchanged pulmonary function could repeat the tests at longer intervals than those showing a decrease in spirometry values. And this is undoubtedly a result with great clinical applicability. It is important to stress that spirometry should not replace the realization of HRCT.

Furthermore, good concordance between examiners for the Bhalla score demonstrates its usefulness as an evaluation criterion for tomographic changes during longitudinal follow-up of patients with CF.

In relation to the limitations of the study it is important to note that this is a retrospective study in a single referral service with a relatively small number of patients, which may limit the generalization of results. Nevertheless, based on the results, we cannot definitively exclude the extrapolation of the findings in this study, though it certainly should be a matter to be explored further in future studies with a prospective design.

Finally, the notion of complementarity of clinical, radiological and functional information will contribute to the development of more discerning monitoring protocols aimed at the overall wellbeing of individuals with CF. These protocols, should consider patients with CF as well as other chronic diseases, who will be submitted to numerous radiological tests and must therefore be protected from the effects of ionizing radiation, either by reducing the dose during the exams or more careful requests for such. It should be noted that the standardization of the frequency should not be instituted by service protocols and that each patient should be evaluated on an individual basis, although spirometry could be an important ally in the decision making regarding the time to perform examination.

\section{Resumo}

Correlação entre escore de Bhalla e espirometria em crianças e adolescentes com fibrose cística

Objetivo: correlacionar os achados da tomografia computadorizada de alta resolução (TCAR) do tórax, com base no escore de Bhalla, com os dados clínicos e a espirometria em crianças e adolescentes com fibrose cística (FC), além de estudar a concordância entre dois médicos radiologistas para o escore de Bhalla e suas categorias. 
Métodos: foram avaliados os prontuários e os exames de 23 pacientes do ambulatório. Os itens avaliados foram idade, peso, altura, escore $Z$ altura/idade, escore $Z$ peso/ idade, índice de massa corpórea (IMC), saturação de $\mathrm{O}_{2}$, espirometria e escore de Bhalla.

Resultados: os pacientes avaliados tinham média de idade de 17,4 $\pm 5,7$ anos, sendo 15 do sexo feminino e 8 do sexo masculino. Houve boa correlação entre o escore de Bhalla e a espirometria $\left(C V F-r=0,718, p<0,001 ; V E F_{1}-r=\right.$ $0,830, \mathrm{p}<0,001 ;$ FEF 25-75\%-r = 0,786, $\mathrm{p}<0,001 ; \mathrm{VEF}_{1} /$ $\mathrm{CVF}-\mathrm{r}=0,714, \mathrm{p}<0,001)$. Nota-se, ainda, que alguns pacientes com FEF $25-75 \%>70 \%$ já apresentavam alterações na nota final do escore de Bhalla. Na análise da concordância entre os examinadores, foi encontrado coeficiente kappa de 0,81 ( $\mathrm{p}<0,001)$ e coeficiente de correlação intraclasse de 0,98.

Conclusão: a boa correlação do escore de Bhalla com as provas de função pulmonar confirma a sua utilidade na avaliação e no acompanhamento dos pacientes com FC, podendo ser utilizado tanto para pacientes que são incapazes de realizar a espirometria quanto para uma análise em conjunto dos dois exames, uma vez que a TCAR mostra alterações precoces em pacientes com espirometrias normais.

Unitermos: fibrose cística; tomografia; espirometria; criança; adolescente.

\section{References}

1. Shwachman H, Kulczycki LL. Long-term study of one hundred five patients with cystic fibrosis; studies made over a five- to fourteen-year period. AMA J Dis Child. 1958;96(1):6-15.

2. Brasfield D. Hicks G. Soong S. Tiller RE. The chest roentgenogram in cystic fibrosis: a new screening system. Pediatrics. 1979;63(1):24-9.

3. Bhalla M, Turcios N, Aponte V, Jenkins M, Leitman BS, McCauley DI et al. Cystic fibrosis: scoring system with thin-section CT. Radiology. 1991;179(3):783-8.

4. Assis I, Camargos PAM, Reis FJC, Sulmonett N, Carneiro APS. Assessing correlations between spirometry and Shwachman-Kulczycki score in children and adolescents. Pediatr Pulmonol. 2003;36(4):305-9.
5. Stollar F, Adde FV, Cunha MT, Leone C, Rodrigues JC. Shwachman-Kulczycki score still useful to monitor cystic fibrosis severity. Clinics (São Paulo). 2011;66(6):979-83.

6. Van Beek EJ, Hill C, Woodhouse N, Fichele S, Fleming S, Howe B et al. Assessment of lung disease in children with cystic fibrosis using hyperpolarized 3-Helium MRI: comparison with Shwachman score, ChrispinNorman score and spirometry. Eur Radiol. 2007;17(4):1018-24.

7. O'Sullivan BP, Freedman SD. Cystic fibrosis. Lancet. 2009;373(9678):1891904.

8. Lucaya J, Piqueras J, García-Peña P, Enríquez G, García-Macías M, Sotil J. Low-dose high-resolution CT of the chest in children and young adults: dose, cooperation, artifact incidence, and image quality. AJR Am J Roentgenol. 2000;175(4):985-92.

9. Long FR. High-resolution computed tomography of the lung in children with cystic fibrosis: technical factors. Proc Am Thorac Soc. 2007;4(4):306-9.

10. Freire ID, Abreu e Silva FA, Araújo MA. Comparison among pulmonary function test results, the Shwachman-Kulczycki score and the Brasfield score in patients with cystic fibrosis. J Bras Pneumol. 2008;34(5):280-7.

11. Goris ML, Zhu HJ, Blankenberg F, Chan F, Robinson TE. An automated approach to quantitative air trapping measurements in mild cystic fibrosis. Chest. 2003;123(5):1655-63

12. Demirkazik FB, Ariyürek OM, Ozçelik U, Göçmen A, Hassanabad HK, Kiper N. High resolution CT in children with cystic fibrosis: correlation with pulmonary functions and radiographic scores. Eur J Radiol. 2001;37(1):549 .

13. American Thoracic Society. Standardization of spirometry, 1994 update. Am J Respir Crit Care Med. 1995;152(3):1107-36.

14. Polgar G, Promadhat V. Pulmonary function testing in children: techniques and standards. Philadelphia: WB Saunders; 1971.

15. Miller MR, Hankinson J, Brusasco V, Burgos F, Casaburi R, Coates A et al. Standardisation of spirometry. Eur Respir J. 2005;26(2):319-38.

16. Sociedade Brasileira de Pneumologia e Tisiologia. Diretrizes para teste de função pulmonar. J Bras Pneumol. 2002;28(Supl 3):S1-S238.

17. Helbich TH, Heinz-Peer G, Fleishmann D, Wojnarowski C, Wunderbaldinger P, Huber S et al. Evolution of CT findings in patients with cystic fibrosis AJR Am J Roentgenol. 1999;173(1):81-8.

18. Robroeks CM, Roozeboom MH, de Jong PA, Tiddens HA, Jöbsis Q, Hendriks $\mathrm{HJ}$ et al. Structural lung changes, lung function, and non-invasive inflammatory markers in cystic fibrosis. Pediatr Allergy Immunol. 2010;21(3):493-500.

19. Brody AS, Molina PL, Klein JS, Rothman BS, Ramagopal M, Swartz DR. High-resolution computed tomography of the chest in children with cystic fibrosis: support for use as an outcome surrogate. Pediatr Radiol. 1999;29(10):731-5.

20. Dodd JD, Barry SC, Barry RB, Gallagher CG, Skehan SJ, Masterson JB. Thinsection CT in patients with cystic fibrosis: correlation with peak exercise capacity and body mass index. Radiology. 2006;240(1):236-45.

21. Marchant JM, Masel JP, Dickinson FL, Masters IB, Chang AB. Application of chest high-resolution computer tomography in young children with cystic fibrosis. Pediatr Pulmonol. 2001;31(1):24-9.

22. De Jong PA, Nakano Y, Lequin MH, Mayo JR, Woods R, Paré PD et al. Progressive damage on high resolution computed tomography despite stable lung function in cystic fibrosis. Eur Respir J 2004:23(1):93-7.

23. Cademartiri F, Luccichenti G, Palumbo AA, Maffei E, Pisi G, Zompatori M et al. Predictive value of chest $\mathrm{CT}$ in patients with cystic fibrosis: a singlecenter 10-year experience. AJR Am J Roentgenol. 2008;190(6):1475-80. 